\title{
Reduction of Energy Consumption and GHGs Emission in Investment Casting Process by Application of a New Casting Method
}

\author{
Xiaojun Dai ${ }^{1}$, Mark Jolly ${ }^{1}$, Binxu Zhang ${ }^{1}$ \\ ${ }^{1}$ School of Mechanical Engineering, University of Birmingham, UK
}

\begin{abstract}
In conventional investment casting process of aluminium alloys for the application of the aerospace industry, to assure the quality of the final casting, usually the foundry uses large runner system which results in low yield, high energy consumption and high GHGs emission. In one case of this investigation, the yield is between $5 \sim 10 \%$ which means that the current casting process wastes large amount of energy and generates lots of scraps. By applying a new casting method, the bulky runner system and the melting/holding time are significantly reduced, the quality of the casting is improved, and in the meantime the related energy consumption and GHGs emission are significantly decreased. In the investigation, the energy efficiencies and GHGs emission between the current and traditional processes are calculated and compared.
\end{abstract}

\section{Introduction}

As one of the conventional casting process, Investment Casting Process (ICP) and its applications can be traced to thousand years ago [1]. In current casting industry, ICP still plays an important role in the production of small and precious castings with high quality requirements in automobile and aerospace industries. Both casting quality and manufacturing costs which mainly consist of energy costs have crucial effects on the competitiveness of castings in the market. In the production of aluminium alloy castings using ICP, the energy cost and energy efficiency of a casting facility depend mainly on the efficiency of its melting and heat treating performance. In association with the two performances, more than $60 \%$ of the total process energy costs are symbolised in a typical casting facility [2]. Additionally, in conventional ICP of aluminium alloys for the application of the aerospace, to assure the quality of the final casting, typically the foundry uses huge runner system including big risers/feeders which cause low yield, creates lots of scraps and generates high energy consumption. Consequently, there are huge opportunities for casting industry to choose the best practices for potential energy saving. Furthermore, the reasons such as the stringent limitation of environmental legislation in Europe and the pressure of the rising energy price force the casting industry to reduce the energy consumption and greenhouse gases (GHGs) emission.

To reduce GHGs emission and protect the environment is another vital issue that the casting industry is facing. It was reported that when consuming each $\mathrm{MWh}$ of natural gas in producing aluminium castings the GHGs emission produce $182.80 \mathrm{~kg}$ of $\mathrm{CO}_{2}, 0.22 \mathrm{~kg} \mathrm{NO}$, $0.0047 \mathrm{~kg}$ of particulate (when producing one tonne of aluminium castings, combustionrelated air GHGs emission are $304.51 \mathrm{~kg}$ of $\mathrm{CO}_{2}, 0.21 \mathrm{~kg}$ of $\mathrm{CO}, 0.96 \mathrm{~kg}$ of $\mathrm{SO}_{\mathrm{x}}, 0.63 \mathrm{~kg}$ of $\mathrm{NO}_{\mathrm{x}}, 0.85 \mathrm{~kg}$ of organics and $0.27 \mathrm{~kg}$ of particulate) [3]. Therefore, implementation of new 
facility and process to reduce the energy consumption and GHGs emission, increase energy efficiency and improve the quality of castings can significantly help the casting industry to promote the competitiveness and reduce the environment pollution.

The experts from University of Birmingham and a local company, - N-Tec LTD. have coinvented a new CRIMSON (Constrained Rapid Induction Melting Single Shot Up-Casting) process [4]. The purposes to develop this process are not only to decrease the energy consumption and to improve the casting quality but also to reduce the GHGs emission in light-metal casting industry. As shown in Figure 1, after the metal melted the closed crucible in the induction furnace is transferred to the up-caster and the melted metal is pushed up using a computer controlled anti-gravity filling method to fill the mould. Due to a characteristic of quick melting, transfer and filling in the new process, the holding time of melted metal is minimised, huge amount of energy saving and reduction of GHGs emission are achieved.

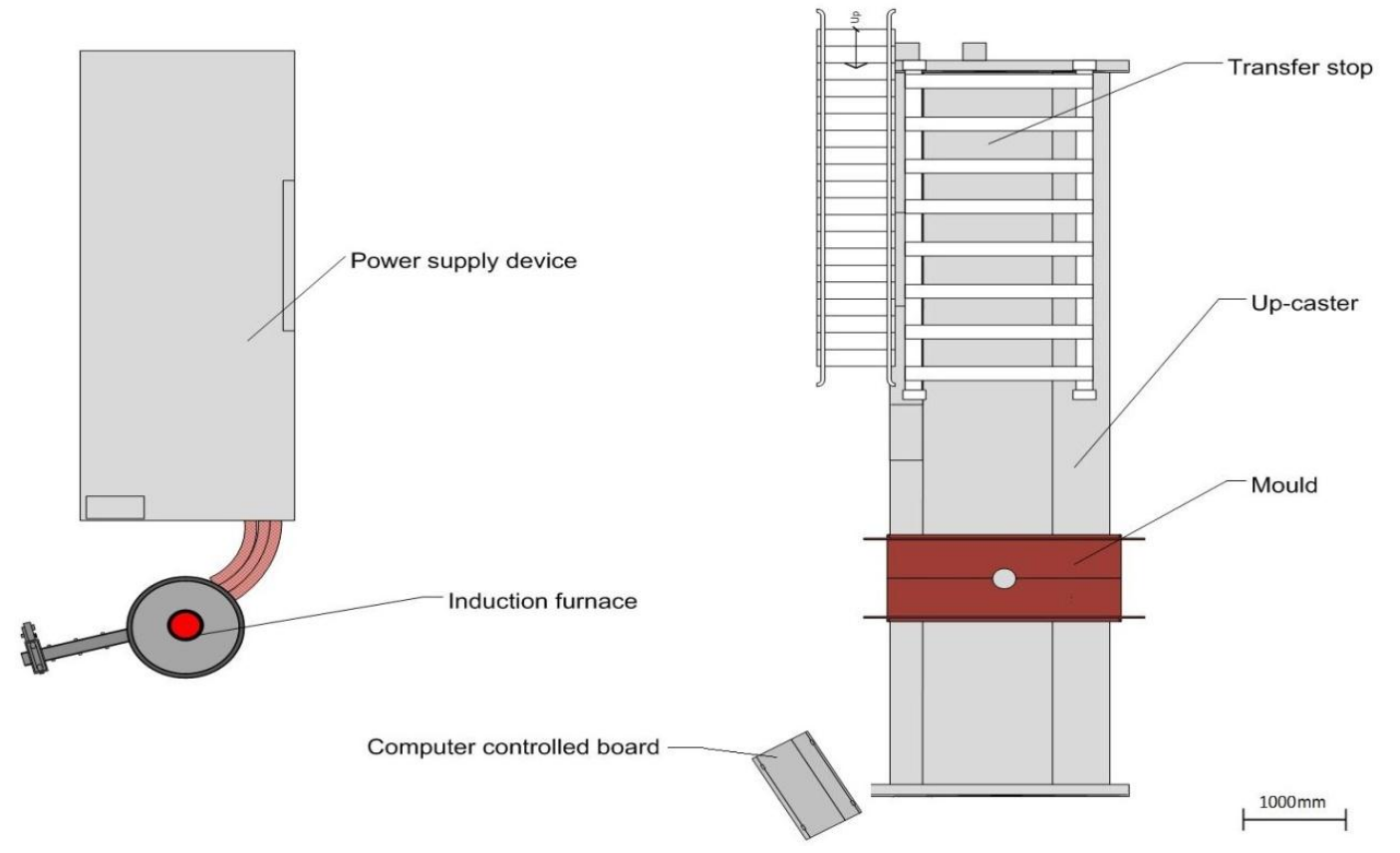

Figure 1 Schematic plan of the new casting process facility

In this paper, a conventional ICP from a local company, Aeromet LTD. was investigated and it was compared with the new process. We mainly focused on the energy aspects and GHGs emission of the melting and casting processes, other issues such as energy consumption of wax model formation and heating solution etc. will be further investigated later. The analysis and comparison were completed to see what the difference of main energy consumption and GHGs emission between the current ICP and the new process. Hence, the potential energy saving and available reduction of GHGs emission for the new process could be found.

\section{Conventional Investment Casting Process}

From Figure 2, the ICP is a complex casting process. Most stages of the process include the energy consumption contents. However, the most energy-consumptive part of the ICP is in 
the metal melting/holding stages in a crucible furnace where the yield also has a vital effect on the energy efficiency and GHGs emission.

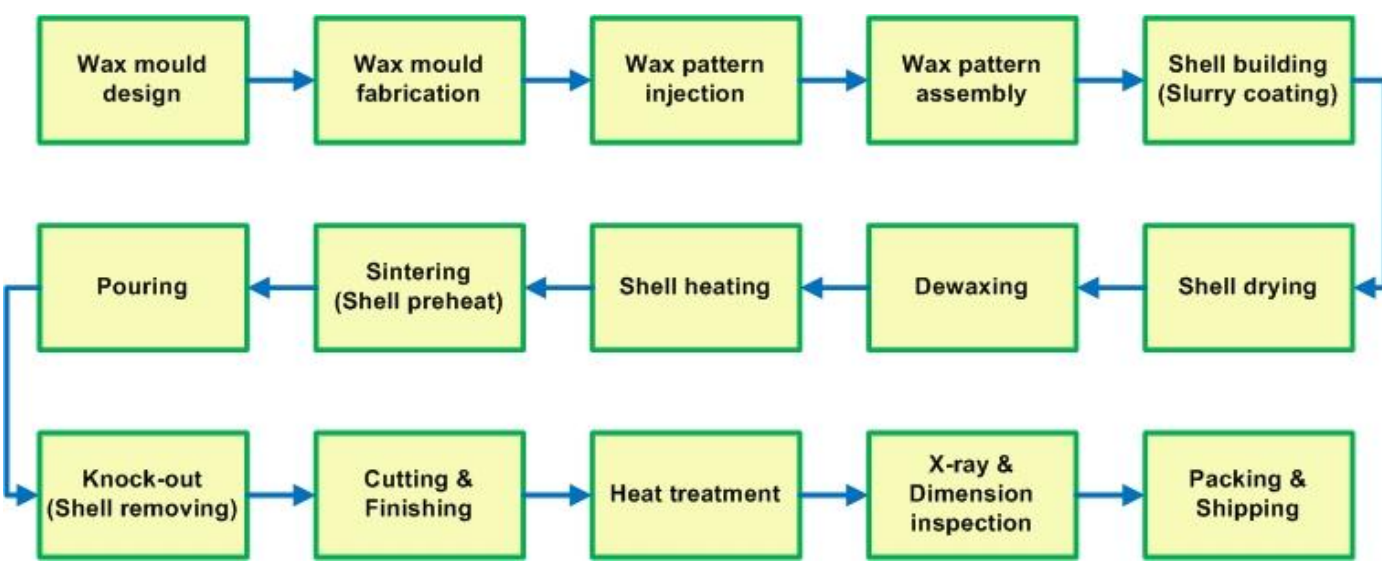

Figure 2 Flow chart of a typical Investment Casting Process (ICP) in a foundry

\section{Comparison of the new casting process with the conventional ICP}

In comparing the new process with the conventional ICP, except the melting and pouring methods, other steps are basically same. The former uses induction furnace and electricity to melt the alloys, and uses bottom filling method to fill a mould. The later mostly uses crucible furnace and gas to melt the alloys and uses top (gravity) pouring method to fill a mould.

\section{Case study - an aluminium alloy casting sample from Aeromet LTD 4.1 Melting process and facility in Aeromet LTD.}

The Aeromet LTD. mainly produces precise and high quality aluminium alloy castings for the applications of the Aerospace Industry. It is currently using the conventional crucible furnaces, each with a capacity of $400 \mathrm{~kg}$. The natural gas is used to heat and melt aluminium alloys. The furnace has an average 2.5 hours' melting period and 1.5 hours' holding period. The overheating temperature of A356 aluminium alloy is $780{ }^{\circ} \mathrm{C}$. The normal pouring temperature is $700{ }^{\circ} \mathrm{C}$. The typical crucible furnace is shown in Figure 3.

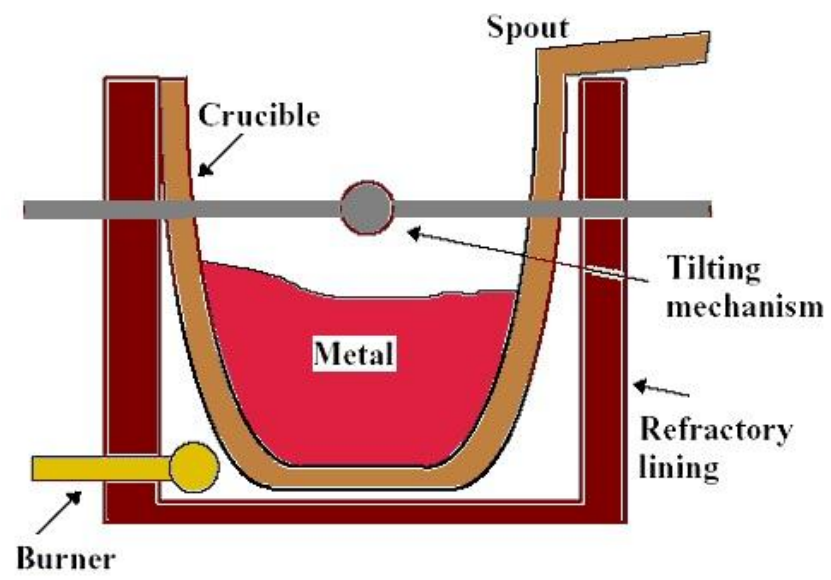

Figure 3 A typical crucible furnace 


\subsection{Casting sample}

An A365 aluminium alloy component "Filter Housing" is used as a sample to investigate the difference of three issues between the conventional ICP and the new melting processes: The first one is the different energy consumption during melting/holding periods; The second one is the different energy consumption due to different yields; The third one is the different GHGs emission. The sample has a profile of $150 \mathrm{~mm}$ x $140 \mathrm{~mm}$ x $130 \mathrm{~mm}$, with a weight of $0.81 \mathrm{~kg}$.

\section{Thermodynamic analysis, energy consumption and GHGs emission}

Aluminium alloy melting process in a crucible furnace using gas as a source has complex physical-chemical phenomena which include gas combustion, drossing, phase change and heat/energy transfer (radiation, conduction and convection). In the induction furnace of the new process, round billet with required size and quality is just re-melted using electricity without drossing within very short time and therefore there is less heat/energy loss. In general, some of the thermodynamic parameters can be measured easily such as temperature and pressure and in the mean time some parameters are difficult to measure such as the heat loss in the way of radiation and convection. Thermodynamic analysis of the energy balance during the melting process in a crucible furnace or an induction furnace based on the experimental results can be achieved [5]. These experimental results and the related thermodynamic analysis can be a reference to help casting industry to improve the energy efficiency and reduce the GHGs emission.

In this paper, an aluminium melting furnace from a local company - Aeromet LTD., and an induction furnace in the new process are used to implement the experiments and thermodynamic analysis. The schematics of energy balance in the aluminium melting furnaces of both Aeromet and the new process are shown in Figure 4(a) and Figure 4(b), respectively. The experiment and analysis of energy efficiency is based on the following assumptions:

1) The properties of A356 alloy are different with those of pure aluminium. Based on the calculation simplicity, both aluminium ingots used in crucible furnace and induction furnace are assumed as pure aluminium;

2) The system is considered as continuous steady state which includes fuel flow, air flow rate, melting rate, flue gas parameters and thermal conduction through furnace wall;

3) The fuel and combustion products behave as ideal gas mixtures;

4) The environment temperature and pressure are taken as standard $25^{\circ} \mathrm{C}$ and $1 \mathrm{~atm}$ correspondingly, which are also applied to gas, combustion air and aluminium ingot;

5) The electric energy consumption is only applied to the part of induction heating in induction furnaces, not applied to the motors and control devices which are neglected for the convenient calculation and simplicity;

6) The natural gas composition is considered as pure propane due to the small amount of $\mathrm{N}_{2}, \mathrm{CO}_{2}, \mathrm{H}_{2} \mathrm{~S}$ and $\mathrm{H}_{2} \mathrm{O}$ included;

7) The lost metal during drossing is neglected for the calculation simplicity. 
The energy balance of the furnace at Aeromet in Figure 4(a) can be expressed as [6]:

$$
\begin{array}{ll}
\boldsymbol{E}_{\text {in }}=\boldsymbol{E}_{\text {out }} & 4.1 \\
\boldsymbol{E}_{\text {in }}=\boldsymbol{Q}_{\text {fuel }}+\boldsymbol{Q}_{\text {ingot }}+\boldsymbol{Q}_{\text {comb air }} & 4.2 \\
\boldsymbol{E}_{\text {out }}=\boldsymbol{Q}_{\text {melt }}+\boldsymbol{Q}_{\text {mis }}=\left(\boldsymbol{Q}_{\text {ingot }}+\Delta \boldsymbol{Q}_{\boldsymbol{A l}}\right)+\boldsymbol{Q}_{\text {mis }} & 4.3 \\
\boldsymbol{Q}_{\text {mis }}=\boldsymbol{E}_{\text {in }}-\Delta \boldsymbol{Q}_{\boldsymbol{A l}} & 4.4 \\
\boldsymbol{\eta}=\Delta \boldsymbol{Q}_{\boldsymbol{A l}} / \boldsymbol{Q}_{\text {fuel }} & 4.5
\end{array}
$$

Where, $\boldsymbol{E}_{\boldsymbol{i n}}$ is the energy input of the furnace system; $\boldsymbol{E}_{\boldsymbol{o u t}}$ is the energy output of the furnace system; $\boldsymbol{Q}_{\text {fuel }}$ is the energy generated from fuel combustion; $\boldsymbol{Q}_{\text {ingot }}$ is the energy generated from aluminium ingot, here $\boldsymbol{Q}_{\text {ingot }}=0 ; \boldsymbol{Q}_{\text {comb air }}$ is the energy generated from combustion air, here $\boldsymbol{Q}_{\text {comb air }}=0 ; \boldsymbol{Q}_{\text {melt }}$ is the heat transferred to the melted metal; $\Delta \boldsymbol{Q}_{\boldsymbol{A l}}$ is the energy variation of the metal from ingot to melted metal; $\boldsymbol{Q}_{m i s}$ is all the energy loss during the melting process in a furnace chamber; $\boldsymbol{\eta}$ is the energy efficiency of the furnace at Aeromet;

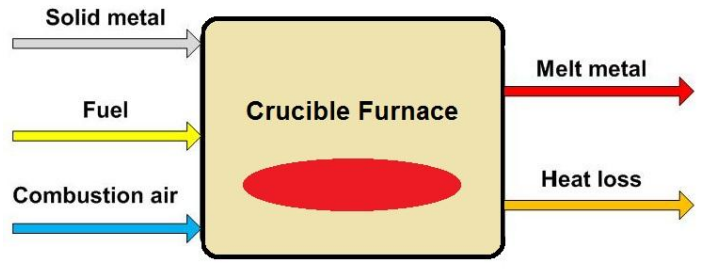

(a)

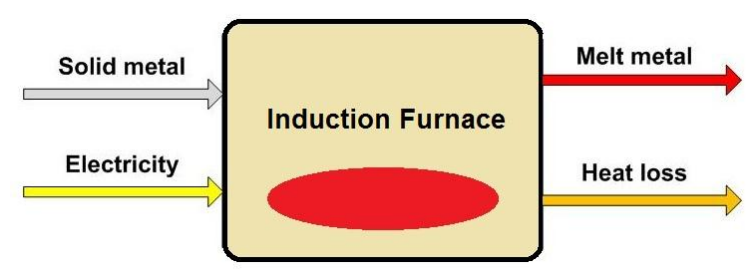

(b)

Figure 4 Schematic of energy balance (a) in the crucible furnace of Aeromet LTD; (b) in the induction furnace of the new process.

The energy balance of the induction furnace of the new process in Figure 4(b) can be expressed in a bit different type: equations 4.1 and 4.4 are the same; $4.2,4.3$ and 4.5 can be revised to as follows: $\boldsymbol{E}_{\text {in }}=\boldsymbol{Q}_{\text {electricity }}+\boldsymbol{Q}_{\text {ingot }}$

$$
\begin{aligned}
& \boldsymbol{E}_{\text {out }}=\boldsymbol{Q}_{\text {melt }}+\boldsymbol{Q}_{\text {mis }}=\left(\boldsymbol{Q}_{\text {ingot }}+\Delta \boldsymbol{Q}^{\prime}{ }_{\text {Al }}\right)+\boldsymbol{Q}_{\text {mis }} \\
& \boldsymbol{\eta}_{c}=\Delta \boldsymbol{Q}^{\prime}{ }_{\text {il }} / \boldsymbol{Q}_{\text {electricity }}
\end{aligned}
$$

Where, $\boldsymbol{Q}_{\text {electricity }}$ is the energy generated from electricity; $\boldsymbol{Q}_{\text {ingot }}$ is the energy generated from aluminium ingot, here $\boldsymbol{Q}_{\text {ingot }}=0 ; \boldsymbol{\eta}_{\boldsymbol{c}}$ is the energy efficiency of the induction furnace;

It should be pointed out here that the round billets used in the new process are provided by Aeromet LTD. The compromising method in this project is that the scrape and ingot are remelted and recast into circular shape with required chemical compositions [7]. The energy consumption and GHGs emission occurred due to re-melting and recasting are not audited in this paper. GHGs emission of the two processes during melting/holding can be calculated based on the energy consumption or yield. 


\section{Experiments, assessment and discussion}

The energy consumption at Aeromet LTD was investigated where natural gas was used to melt and hold the A356 alloys in the crucible furnaces. The consumption of gas was recorded in Table 1.

\begin{tabular}{|c|c|c|}
\hline Energy type & Energy consumption of melting and holding A356 & Energy density by mass \\
\hline Natural gas & $\begin{array}{l}236.25 \mathrm{~m}^{3} . \text { tonne }^{-1}\left(\text { measurement accuracy }^{ \pm} 1.0\right) \\
\boldsymbol{Q}_{\text {fuel }}=8.65{\mathrm{MJ} . \mathrm{kg}^{-1}}\left(2401.88 \mathrm{kWh} \cdot \mathrm{knne}^{-1}\right)\end{array}$ & $45.57 \mathrm{MJ} . \mathrm{kg}^{-1}$ \\
\hline
\end{tabular}

Table 1 Actual consumption of gas at Aeromet LTD where a crucible furnace is used

From Table 1, the actual energy consumption $\boldsymbol{Q}_{\text {fuel }}$ for melting and holding A356 \left. aluminium alloys in Aeromet is $8.65{\mathrm{MJ} . \mathrm{kg}^{-1}(2401.88 \mathrm{kWh} . \text { tonne }}^{-1}\right)$. Without considering the chemical reaction, slag formation, radiation and other heat losses, the theoretical calculation of the energy consumption for heating A356 alloy to $780{ }^{\circ} \mathrm{C}$ is as follows:

$$
\Delta \boldsymbol{Q}_{\boldsymbol{A l}}=\boldsymbol{m} \boldsymbol{C}_{\boldsymbol{m} \mathbf{1}}\left(\boldsymbol{T}_{\boldsymbol{m}}-\boldsymbol{T}_{\mathbf{1}}\right)+\boldsymbol{E}_{\boldsymbol{f}}+\boldsymbol{m} \boldsymbol{C}_{\boldsymbol{m} \mathbf{2}}\left(\boldsymbol{T}_{\mathbf{2}}-\boldsymbol{T}_{\boldsymbol{m}}\right)=1198.2 \mathrm{~kJ} \cdot \mathrm{kg}^{-1}=332.8 \mathrm{kWh} . \text { tonne } \mathrm{e}^{-1}
$$

Here, $\Delta \boldsymbol{Q}_{\boldsymbol{A l}}$ is the heat that is needed to heat and melt the Al alloys; $\boldsymbol{m}$ is the mass of the $\mathrm{Al}$ alloy; $\boldsymbol{C}_{\boldsymbol{m} \mathbf{1}}$ is the specific heat for solid A356 Al alloys, $1.07 \mathrm{~kJ} \mathrm{~kg}^{-1} \cdot{ }^{\circ} \mathrm{C}^{-1}$ [8]; $\boldsymbol{C}_{\boldsymbol{m} \boldsymbol{2}}$ is the specific heat for liquid A356 Al alloys, $1.05 \mathrm{~kJ}_{\mathrm{kg}}{ }^{-1} \cdot{ }^{\circ} \mathrm{C}^{-1}[8] ; \boldsymbol{T}_{\boldsymbol{m}}$ is the melting temperature of A356 Al alloys, $596{ }^{\circ} \mathrm{C}$ [9]; $\boldsymbol{T}_{\mathbf{1}}$ is the environment temperature, $25{ }^{\circ} \mathrm{C} ; \boldsymbol{T}_{\mathbf{2}}$ is the superheat

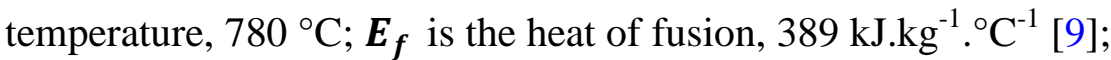

The thermal efficiency of crucible furnace for melting and holding A356 in Aeromet is $\boldsymbol{\eta}=\Delta \boldsymbol{Q}_{\text {Al }} / \boldsymbol{Q}_{\text {fuel }}=332.8 / 2401.88=13.86 \%$. Experimental parameters for the new facility are given in Table 2.

\begin{tabular}{|c|c|c|c|c|}
\hline Energy type & $\begin{array}{l}\text { Energy consumption of } \\
\text { melting A356 }\end{array}$ & $\begin{array}{l}\text { Weight of metal } \\
\text { charge }\end{array}$ & $\begin{array}{l}\text { Melting } \\
\text { temperature }\end{array}$ & Melting time \\
\hline Electricity & $550 \mathrm{kWh} \cdot$ tonne $^{-1}$ & $5.95 \mathrm{~kg}$ & $729^{\circ} \mathrm{C}$ & $\sim 3$ minutes \\
\hline Accuracy (\%) & \pm 0.02 & \pm 0.5 & \pm 2.9 & \pm 0.001 \\
\hline
\end{tabular}

\section{Table 2 Actual consumption of electricity for the new facility}

Without considering other heat losses, the theoretical calculation of the energy consumption for heating A356 alloy to $729^{\circ} \mathrm{C}$ is as $\Delta \boldsymbol{Q}^{\prime}{ }_{\boldsymbol{A l}}=\boldsymbol{m} \boldsymbol{C}_{\boldsymbol{m} \mathbf{1}}\left(\boldsymbol{T}_{\boldsymbol{m}}-\boldsymbol{T}_{\mathbf{1}}\right)+\boldsymbol{E}_{\boldsymbol{f}}+\boldsymbol{m} \boldsymbol{C}_{\boldsymbol{m} 2}\left(\boldsymbol{T}_{2}-\boldsymbol{T}_{\boldsymbol{m}}\right)=$ $1145 \mathrm{~kJ} . \mathrm{kg}^{-1}=318 \mathrm{kWh}$.tonne ${ }^{-1}$; The thermal efficiency of induction furnace for the new process is calculated as [10] $\boldsymbol{\eta}_{\boldsymbol{c}}=\Delta \boldsymbol{Q}^{\prime}{ }_{\boldsymbol{A l}} / \boldsymbol{Q}^{\prime}{ }_{\text {fuel }}=318 / 550=57.82 \%$. In consideration of conversion efficiency of $50 \%$ in a natural gas-fired power plant $[11,12]$, for melting A356 in new process the total energy consumption is $550 \mathrm{kWh} \cdot \mathrm{tonne}^{-1} / 50 \%=1100 \mathrm{kWh} \cdot$ tonne $^{-1}$ and the total thermal efficiency can be calculated as $\boldsymbol{\eta}^{\prime}{ }_{c}=57.82 \% \times 50 \%=28.91 \%$.

The thermal efficiency of the crucible furnace using natural gas at Aeromet is $\boldsymbol{\eta}=13.86 \%$. In comparison with the crucible furnace, the total thermal efficiency of induct furnace for the new process is $\boldsymbol{\eta}^{\prime}{ }_{\boldsymbol{c}}=28.91 \%$. It means that a large amount of energy was wasted in the current ICP using in Aeromet due to using an old melting process. It is suggested that if the current melting and holding process at Aeromet could be replaced by the new single shot 
melting method (induction heating), the thermal efficiency will increase up to $15.05 \%$. When melting the same amount of A356 alloy, it is estimated that 4.69 GJ.tonne ${ }^{-1}$ (1.30 MWh.tonne ${ }^{-}$

${ }^{1}$ ) could be saved and the reduction of the GHGs emission such as $237.64 \mathrm{~kg}$.tonne $\mathrm{e}^{-1}$ of $\mathrm{CO}_{2}$, $0.286 \mathrm{~kg}$. tonne $^{-1}$ of $\mathrm{NO}_{\mathrm{x}}$ and $0.0061 \mathrm{~kg}$. tonne $^{-1}$ of particulate could be achieved.

In addition, the current ICP in Aeromet for producing the casting sample has a yield of $7.5 \%$. In contrast with the current ICP, the new process with a re-designed runner system has a yield of $54.5 \%$ where the four samples have a weight of $3.24 \mathrm{~kg}$ and the total weight including runner system is $5.95 \mathrm{~kg}$. If using the traditional ICP to produce the four samples, the runner system will have the weight of $3.24 \mathrm{~kg} / 7.5 \%=43.2 \mathrm{~kg}$. It indicates that there is an increase of scrap $43.2 \mathrm{~kg}-5.95 \mathrm{~kg}=37.25 \mathrm{~kg}$ in the traditional ICP. The wasted energy could be as $2401.88 \mathrm{kWh}$.tonne $\mathrm{H}^{-1} \times 1000^{-3} \times 37.25 \mathrm{~kg}=89.47 \mathrm{kWh}$ which means $27.61 \mathrm{MWh}$ could be saved and reduction of GHGs emission such as $5,047.86 \mathrm{~kg}$ of $\mathrm{CO}_{2}, 6.07 \mathrm{~kg}$ of $\mathrm{NO}_{\mathrm{x}}$ and $0.13 \mathrm{~kg}$ of particulate could be achieved in producing one tonne of the A356 samples.

Another reason for recommending the new method instead of using crucible furnace at Aeromet is that the new process uses a rapid filling method where in the induction furnace the alloy is heated to the required temperature with high power, avoiding holding long time and hence reducing the potential energy wastage. In the mean time, due to the swift melting and filling methods, the chance of oxide film formation on the surface of the melted alloy and the potential time for hydrogen absorption are significantly reduced. The quality of the casting can be acquired accordingly.

\section{Conclusions}

The investigation of energy consumption and GHGs emission on both traditional ICP and the new processes were implemented. The related experimental results on the energy efficiency have shown a big difference between them. If the conventional melting furnace used in Aeromet could be replaced by the new method, 4.69 GJ.tonne $^{-1}\left(1.30 \mathrm{MWh}^{-t_{0}} \mathrm{Wn}^{-1}\right)$ of the energy could be saved during melting the aluminium alloy. The estimated production cost could be reduced by 98.80 pounds. tonne ${ }^{-1}\left(7.6 \mathrm{p} . \mathrm{kWh}^{-1}\right)$. The GHGs emission i.e. $237.64 \mathrm{~kg}$. tonne $^{-1}$ of $\mathrm{CO}_{2}, 0.286 \mathrm{~kg}$.tonne ${ }^{-1}$ of $\mathrm{NO}_{\mathrm{x}}$ and $0.0061 \mathrm{~kg}$.tonne ${ }^{-1}$ of particulate could be reduced.

In the case of the "Filter Housing" A356 sample where using the new casting process, the potential energy saving for producing each tonne castings could be $27.61 \mathrm{MWh}$. The estimated production cost could be reduced by 2098 pounds $\left(7.6 \mathrm{p} . \mathrm{kWh}^{-1}\right)$ and the GHGs emission such as $5,047.86 \mathrm{~kg}$ of $\mathrm{CO}_{2}, 6.07 \mathrm{~kg}$ of $\mathrm{NO}_{\mathrm{x}}$ and $0.13 \mathrm{~kg}$ of particulate could be achieved.

Based on the investigation, the new process is proved to be an effective method in increasing the energy efficiency, reducing the production costs and the GHGs emission.

The energy consumption and energy efficiency for other stages of the ICP will be further investigated in this research project. 


\section{Acknowledgements}

This research project is funded by the Engineering and Physical Sciences Research Council (EPSRC) of the UK under the grant of EP/G060096/1. Many thanks to the University of Birmingham and N-Tec Co. Ltd. for providing the experiment equipment. Acknowledgement will be given to the Aeromet LTD. for providing the data of their current ICP process.

\section{References}

[1] V. Faccenda, Handbook on Investment Casting - The Lost Wax Casting Process for Carat Gold Jewellery Manufacture, 2003, published by World Gold Council, International Technology.

[2] R. Eppich, R.D. Naranjo., Implementation of Metal Casting Best Practices, Report of U.S. Department of Energy, 2007.

[3] N. Margolis, Energy and Environmental Profile of the U.S. Aluminium Industry, report prepared by GNERGETICS, Inc. Columbia, Maryland, U.S. Department of Energy, Office of Industrial Technologies, July 1997.

[4] M. Jolly, Energy Saving in the Foundry Industry by Using the "CRIMSON" Single Shot UPCasting Process, 2010 TMS Annual Meeting \& Exhibition, Febuary 14-18, 2010, Seattle, WA.

[5] T. L, M. Hassan, K. Kuwana, K. Saito, P. King, 2005 Performance of secondary aluminium melting: Thermodynamic analysis and plant-site experiments. Energy 31 1769-1779.

[6] M. A. Rosen, 2009 Exergy-based Analysis and Efficiency Evaluation for an Aluminium Melting Furnace in a Die-casting Plant, Proceedings of the $4^{\text {th }}$ IASME/WSEAS International Conference on ENERGY \& ENVIORMENT (EE’09).

[7] Jolly, M., Dai, X., Energy efficiency improvement by implementation of the novel CRIMSON aluminium casting process TMS2011. Waste Heat Recovery symposium. $27^{\text {th }}-$ Feb to $3^{\text {rd }}$-Mar, 2011, San Diego, USA.

[8] C. Schmitz, Handbook of aluminium recycling: Fundamentals, Mechanical Preparation, Metallurgical Processing, Plant Design, Vulkan-Verlag GmbH, Germany, 2006.

[9] MatWed MATERIALS PROPERTY DATA,

http://www.matweb.com/search/MaterialGroupSearch.aspx

[10] X. Dai, M. Jolly, 2011, Potential energy savings by application of the novel CRIMSON aluminium casting process, Applied Energy (in press).

[11] J. V. Spadaro, L. Langlois, B. Hamilton, 2000, Greenhouse Gas Enission of Electricity Generation Chains - Assessing the Difference, IAEA BULLETIN.

[12] Power station -Wikipedia: http://en.wikipedia.org/wiki/Power_station 